\title{
Seeking Information: Where Do Pregnant Women Go?
}

\author{
Lauren S. Aaronson, PhD, RN \\ Carol Macnee Mural, MSN, RN \\ Susan K. Pfoutz, MS, RN
}

As part of a larger investigation of health behaviors and beliefs during pregnancy, a sample of 529 women were asked to identify their major sources of information about what they should and should not do during their pregnancies. Health care providers and books were cited as first or second most important by the largest number of respondents. When associations between respondent characteristics and preferred information sources were explored, it was found that women of higher socioeconomic status (SES) relied more on books and less on family than did women of lower SES. In addition, having had a previous pregnancy was associated with greater use of one's self as an information source. Although provider characteristics were not associated with choice of information source, women who perceived more support from their providers viewed them as more important sources of information. A similar effect for family was found. Health locus of control beliefs also were related to the relative importance of selected sources of information, while general social support was not.

\section{INTRODUCTION}

Sound health behavior decision-making requires relevant and accurate health knowledge. ${ }^{1-4}$ Knowledge serves as a basis for managing uncertainty, coping with change, and maintaining some control regarding health decisions. ${ }^{3-6}$ To ensure that clients acquire accurate knowledge, health care providers and educators must understand information seeking behavior. Doing so allows health care professionals to consider, predict, and influence the sources of information used by clients.

This article is based on a poster presented at the 1986 American Public Health Association Annual Meeting in Las Vegas, NV. Work on this article was supported by grants awarded to the first author by the Division of Nursing (R01 NU01207) and the National Center for Nursing Research, NIH, (2 R01 NR01207-03), Public Health Service, Department of Health and Human Services. The authors also wish to ack nowledge the Group Health Cooperative of Puget Sound and the Virginia Mason Medical Center for their cooperation during data collection and a grant from the National Center for Health Services Research (R03 HS04440) that, in part, supported data collection for the original study.

Lauren S. Aaronson, Carol Macnee Mural and Susan K. Pfoutz are with the School of Nursing, The University of Michigan.

Address reprint requests to: Lauren S. Aaronson, $\mathrm{PhD}, \mathrm{RN}$, The University of Michigan, School of Nursing, 400 N. Ingalls Building, Ann Arbor, MI 48109. 
Information seeking can be conceptualized as both a component of decision-making about health behavior and as a decison-making process itself. Using a process model approach, Lenz ${ }^{3}$ has suggested that there are several steps in the information search process. The first step is receiving a stimulus. Within Lenz's model, pregnancy can be viewed as a stimulus that signals the need to acquire knowledge. Pregnancy is not only a period of substantial physical and role change, but also a time in which health related behaviors are more salient because they affect both the mother and the developing fetus.

Once a stimulus has been received, information goal setting and the decision to actively seek information ${ }^{3}$ are activated. This in turn leads to search behavior which includes both the extent and the method of search. ${ }^{3}$ The extent of search is reflected in both the quantity and the quality of the search activities; while the method of search may be personal or impersonal, reflecting characteristics of the sources of information used by information seekers. Personal methods would include talking with family and friends and impersonal methods would include use of printed material, media, and individuals unknown to the seeker.

Evidence suggests that the information seeking process is influenced by specific and general prior knowledge, and by the costs of the search behaviors. ${ }^{7}$ Once knowledge is acquired, decisions about the adequacy and usefulness of the information may be influenced by the level of expertise of the information source and by the relationship of the source to the information seeker, ${ }^{3}$ as well as by the perceived role of the information seeker. ${ }^{8}$

Because characteristics of both the information seeker and the information source may influence search behavior, Suchman's ${ }^{9}$ conceptualization of scientific and popular medical orientations also may be useful in exploring information seeking and the sources of information used. Suchman hypothesized that an individual's social orientation is associated with a distinctive medical orientation. Individuals may have either a cosmopolitan social group orientation, which is associated with a scientific medical orientation, or a parochial social orientation which is associated with a popular medical orientation. Studies have yielded mixed support for Suchman's model, largely because it failed to consider cultural content variability within the parochial social group orientation. ${ }^{10,11}$ Nonetheless, characterizing individuals according to Suchman's social and medical orientations could shed light on methods of search behavior. In particular, it would be expected that those individuals with a parochial social and popular medical orientation would use friends, family, and mass media sources of information more than would individuals with a cosmopolitan and scientific orientation.

Studies which indirectly support Suchman's model have demonstrated that an individual's socioeconomic status, age, and locus of control all influence information seeking. In particular, socioeconomic status has been positively related to the extent of information search ${ }^{12}$ and negatively related to the use of personal information sources. ${ }^{12-16}$ Age also has been negatively related to information seeking ${ }^{14,17,18}$ and an internal locus of control about health combined with a high value placed on health, has been positively associated with information search. ${ }^{19}$

Others have found that a belief in chance control is an important predictor of information seeking. ${ }^{20,21}$ In those studies, not only did individuals who scored higher on belief in chance control seek less information, but they also had less knowledge prior to the educational sessions offered than did those who scored lower on belief in 
chance control. Lastly, despite Suchman's emphasis on social orientation, no research on social support effects on information seeking was found.

The study reported here investigated the information seeking behavior of pregnant women to empirically validate the generality of previous findings in other populations and to consolidate findings from those studies within a single study using a population of pregnant women. Specifically, this study examines the association of the use of different sources of information with prior knowledge, social, economic, and personality variables previously shown to be influential on information seeking.

\section{METHODS}

For this investigation secondary analyses of data was conducted from a larger study of health behavior during pregnancy. ${ }^{1}$ The sample of 529 pregnant women was obtained from eight randomly selected private physician practices and three large health care facilities in the Seattle, Washington area. Subjects completed a written questionnaire, followed by a telephone interview, about a variety of health behaviors. All English literate women over 18 years of age appearing for their prenatal appointment on a sample selection day were eligible for the study unless it was their first prenatal visit or they were already in their ninth month of pregnancy. The first restriction ensured a basis for answering questions about their prenatal care provider, and the second was necessary to ensure completing both the mail-back questionnaire and the subsequent telephone interview before the baby was born. Nearly $90 \%$ of the women who were approached agreed to participate in the study. Of these, nearly $80 \%$ returned completed questionnaires.

Demographic data and information about social support and locus of control were collected as part of the written questionnaire. A modified version of the Brandt and Weinert ${ }^{22}$ Personal Resource Questionnaire (PRQ), specific questions about friend, family, and health care provider supportiveness for the various health behaviors, and the Wallston, Wallston \& DeVellis ${ }^{23}$ Multi-Dimensional Health Locus of Control scales (MHLC) were used to measure the later two variables.

The PRQ is a 25 -item measure of social support. The Cronbach's alpha reliability coefficient obtained for this scale with this sample was 0.88 . The MHLC scale consists of three subscales - internal health locus of control (IHLC), powerful others health locus of control (PHLC), and chance health locus of control (CHLC) - that measure an individual's beliefs in the sources of control over their own health outcomes. Reliability coefficients obtained with this sample for these scales were $0.72,0.64$, and 0.69 respectively.

During the telephone interview subjects were asked to identify the sources of information they used to help them know what they "should and should not do during their pregnancy." The women were asked to name their first major information source, then their second major source, and so on for up to five sources of information. Interviewers were instructed to allow subjects to respond freely with whatever source they used. If they did not offer a response to inquiry about a third or later source, they were prompted by the interviewer with suggestions from a list of options excluding those already mentioned.

Two measures were used for information source. The first focused on only the first and second major sources of information cited by the women because these were 
assumed to most validly reflect the woman's real use of information sources. Although more than $80 \%$ of the subjects reported the maximum possible of five sources of information. it was not clear to what extent they were merely complying with the interview situation in naming their fourth and fifth sources.

For better conceptual clarity, and because of small frequencies, some of the choices were collapsed into categories. Television. radio, newspaper, and magazines were combined into a media category. For some analyses, however, the media category was divided into audiovisual and print media. A health care provider category also was created and included physician, nurse, and nurse-midwife. This was done because the choice of one's physician versus one's nurse-midwife or nurse generally was a function of who the woman was seeing as her primary care provider. Thus, for most analyses, the categories of media. books, family. friends, providers, and self were used.

The second measure of information source focused on the relative importance of each source and was calculated by assigning a score of five if the subject chose that source as her first choice, four if a source was the second choice, and so on through zero if the subject did not select that choice. In those instances where a subject indicated the same source, or a source in the same category for more than one choice, only their highest ranking value was assigned to that information source or category. This redundancy primarily affected the categories where separate sources were combined and occurred more often in the latter choices. Only 16 subjects chose the same category of information source for their first and second choices.

\section{SAMPLE}

The 529 women in this sample ranged in age from 18 to 41 years with a mean age of 28.3 years. Most were married $(90.7 \%)$ and were white $(91.3 \%)$. The $9 \%$ who were nonwhite were fairly evenly divided among Blacks. Asians, and others. This was also a fairly well educated, middle class sample. Two-thirds of the women had at least some college education and the median family income was in the $\$ 20,000$ to $\$ 30.000$ range. Three hundred and fifty three $(66.7 \%)$ of the women had been pregnant at least one other time, however $26 \%$ of these $(N=92)$ aborted and/or miscarried all previous pregnancies. Although the demographic characteristics of this sample are not representative of the United States as a whole, they are remarkably representative of the geographic population from which the sample was drawn. King and Snohomish counties in Washington State are more predominantly white and middle class, as well as better educated than elsewhere. ${ }^{24,25}$

\section{RESULTS}

Not surprisingly, the most frequently cited major sources of information were health care providers and books (See Figure 1). These two sources were cited most frequently as both the first and the second most important sources of information. Using the relative importance measure and summing across all subjects, similar findings emerged. Providers topped the list with 1845 points, followed by books ( 1608 points), friends ( 925 points), print media (910 points), family (753 points), self (598 points), and audiovisual media ( 380 points). 


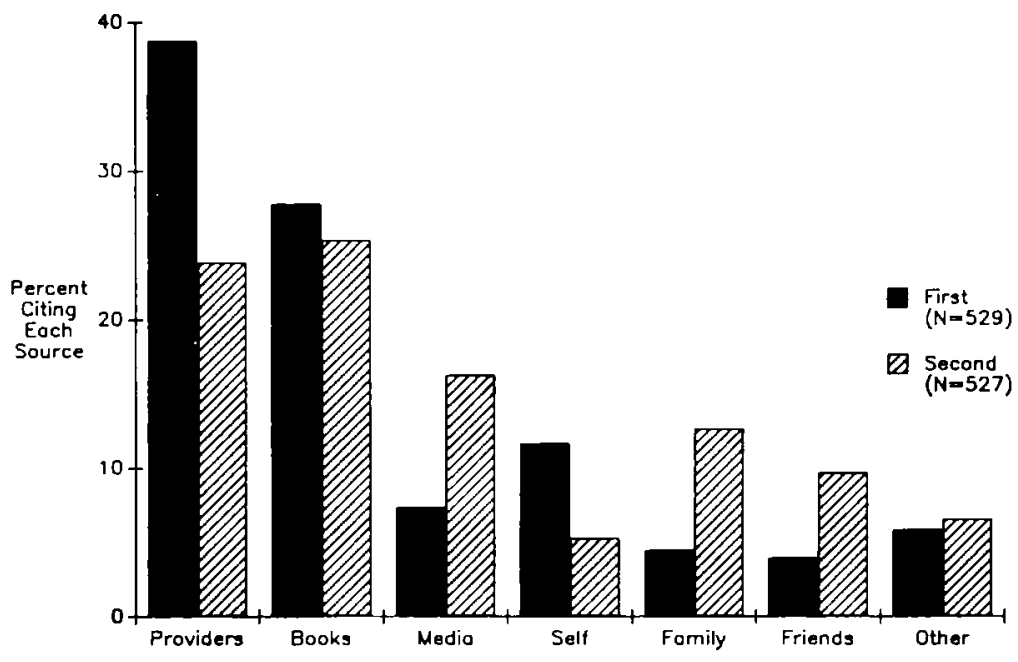

Figure 1. First and Second Major Sources of Information Cited.

Relationships between subject characteristics and sources of information selected were examined both by focusing on the most important sources cited, and on the relative importance of each source based on the reverse ranking scores. The first choice of information source was significantly related to total family income $\left(x^{2}=24.7\right.$, $10 \mathrm{df}, p<0.01)$ and the second choice of information source was significantly associated with education $\left(x^{2}=27.2,15 \mathrm{df}, p<0.03\right)$. While health care providers were cited by the largest number of each income group (40\%-43\%), women from families in the highest income group reported less use of family, friends, and themselves as information sources and somewhat greater use of media and books than did women in the other income groups. Although there was no association between the subjects' education and their first choice of information source, for their second choice, a greater reliance on books and providers by more educated women also was suggested, while less educated women reported family and themselves more frequently as their sources of information. Occupational categories were independent of both the first and second choice of information source.

The associations between the relative importance of each source of information and selected subject characteristics were examined using Pearson Product Moment correlations. These relationships appear in Table 1 . Both education and occupation were negatively related to the relative importance of audiovisual media and family, and positively related to the relative importance of books. Correlations between family income and the relative importance of individual sources of information suggested similar relationships. There was a statistically significant negative relationship between total family income and the importance of family as a source of information and a significant positive relationship between income and books. Print media also was positively associated with total family income, whereas audiovisual media was not significantly related to this socioeconomic status (SES) measure.

Because of the general consistency of these findings, an index of SES was developed 
Table 1. Correlations Among Subject Characteristics and the Relative Importance of the Source of Information

Source of

Information

Subject Characteristics

\begin{tabular}{lccccc}
\hline & Educ & Occ & Income & SES & Age \\
AV media & $-0.16^{\mathrm{c}}$ & $-0.11^{\mathrm{b}}$ & -0.06 & $-0.17^{\mathrm{c}}$ & -0.04 \\
Print media & -0.03 & 0.01 & $0.15^{\mathrm{c}}$ & 0.03 & $0.13^{\mathrm{b}}$ \\
Books & $0.15^{\mathrm{c}}$ & $0.11^{\mathrm{b}}$ & $0.15^{\mathrm{c}}$ & $0.18^{\mathrm{c}}$ & -0.01 \\
Family & $-0.23^{\mathrm{c}}$ & $-0.14^{\mathrm{b}}$ & $-0.19^{\mathrm{c}}$ & $-0.27^{\mathrm{c}}$ & $-0.29^{\mathrm{c}}$ \\
Friends & -0.01 & -0.03 & -0.02 & 0.00 & -0.05 \\
Provider & -0.02 & 0.06 & 0.05 & 0.02 & 0.02 \\
Self & -0.05 & -0.06 & -0.07 & -0.02 & $0.08^{\mathrm{a}}$ \\
\hline
\end{tabular}

a $p<0.05$.

$\mathrm{b}_{p}<0.01$.

$c_{p}<0.001$.

combining the pregnant woman's education (10 levels), the occupation of both the woman and her partner (4 levels each), and total family income ( 8 levels). A simple additive model was used where the subject's levels on each factor were summed. This approach assumed approximately equal weight for each variable, splitting occupation between that for the woman and that for her partner. This index was significantly negatively related to the importance of audiovisual media $(r=-0.17)$ and family $(r=-0.27)$ as sources of information and positively related to the importance of books $(r=0.18)$. Although these correlations are modest in magnitude, the consistency of the findings with different measures of SES strengthens our faith in these results.

Also shown in Table 1 are the relationships between age and the relative importance of the different sources of information. Age was positively related to the importance and use of print media and oneself as sources of information, and negatively related to the importance and use of family.

While the effect of age may reflect some general measure of prior experience and knowledge, having had a previous pregnancy is a better and more specific measure of this concept. Not surprisingly, women who had prior pregnancies cited themselves as a major source of information (both first and second) more often than women who had not been pregnant previously. Primiparous women, on the other hand, selected friends, family and books more often than did women with previous pregnancies (Table 2). While these analyses address distributional differences in choice of information source, t-tests also were performed to assess group differences in the relative importance of each source between those with and those without prior pregnancies. These results were consistent with the cross-tabular findings. Priniparous women ranked books, friends, and family significantly higher and multiparous women ranked themselves, print, and audiovisual media higher. There were no significant differences between the groups in their ranking of providers.

The major personality variable examined in this study was health locus of control. Others $^{19}$ have found effects for an internal health locus of control only in interaction with the value placed on health. However, no significant relationships emerged here when a similar approach for combining health value and internal locus of control was used-i.e., dichotomizing each and creating a four category variable. Nor was the rank- 
Table 2. Associations Between Previous Pregnancy Experience and First and Second Major Sources of Information

\begin{tabular}{|c|c|c|c|c|}
\hline \multicolumn{5}{|c|}{ First Source of Information $(N=495)$} \\
\hline & \multicolumn{2}{|c|}{ Previous Pregnancy } & \multicolumn{2}{|c|}{ No Previous Pregnancy } \\
\hline Information Source & $N$ & $\%$ & $N$ & $\%$ \\
\hline Providers & 127 & 44.4 & 77 & 36.8 \\
\hline Books & 70 & 24.5 & 76 & 36.4 \\
\hline Media & 25 & 8.7 & 14 & 6.7 \\
\hline Family & 13 & 4.5 & 11 & 5.3 \\
\hline Friends & 4 & 1.4 & 17 & 8.1 \\
\hline Self & 47 & 16.4 & 14 & 6.7 \\
\hline \multicolumn{5}{|c|}{ Chi-Square $=30.4,5 \mathrm{df}, p<0.0001$, Cramer's $V=0.25$} \\
\hline \multicolumn{5}{|c|}{ Second Source of Information $(N=489)$} \\
\hline & \multicolumn{2}{|c|}{ Previous Pregnancy } & \multicolumn{2}{|c|}{ No Previous Pregnancy } \\
\hline Information Source & $N$ & $\%$ & $N$ & $\%$ \\
\hline Providers & 70 & 25.2 & 55 & 26.1 \\
\hline Books & 70 & 25.2 & 62 & 29.4 \\
\hline Media & 56 & 20.1 & 30 & 14.2 \\
\hline Family & 29 & 10.4 & 38 & 18.0 \\
\hline Friends & 28 & 10.1 & 23 & 10.9 \\
\hline Self & 25 & 9.0 & 3 & 1.4 \\
\hline \multicolumn{5}{|c|}{ Chi-Square $=20.3,5 \mathrm{df}, p<0.002$, Cramer's $V=0.20$} \\
\hline
\end{tabular}

ing of health as a value related to the relative importance of any of the sources of information. However, the relative importance of providers was negatively related to internal locus of control $(r=-0.11, p<0.05)$, and positively related to powerful others locus of control $(r=0.08, p<0.05)$. Further, internal locus of control was positively related to print media $(r=0.08, p<0.05)$, chance locus of control was positively related to audiovisual media $(r=0.09, p<0.05)$, and powerful others locus of control was negatively related to the relative importance of self $(r=-0.08, p<$ 0.05 ). While these correlations are quite small. they are congruent with expected relationships among these concepts.

The general social support measure (the PRQ) was not significantly related to the relative importance of any of the individual sources of information. However, there were positive correlations between the importance of family $(r=0.11, p<0.05)$ and providers $(r=0.13, p<0.05)$ as information sources and the specific supportiveness the women perceived from these social referents for the health behaviors studied in the larger investigation. In contrast, there was no correlation between the importance of friends as a source of information and the women's perceptions of their supportiveness for the health behaviors.

Lastly, provider characteristics were not found to affect the selection of preferred sources of information. Women selected their primary care giver, whether physician or nurse-midwife, as the provider from whom information was sought. Private practice settings were compared with clinic settings and no setting differences were demonstrated. It should be noted, however, that most physicians in this study were engaged in group practices of two to four physicians which may be somewhat similar to the larger clinic settings, and thus may explain the lack of differences found. 


\section{DISCUSSION}

This study both validates previous findings and common beliefs with respect to information seeking, and illustrates the use of multiple sources of information. The data presented suggest pregnant women actively search for information beyond that offered by their health care provider. However, the predominance of health care providers as major sources of information merits special at tention.

Studies of context variables in information seeking frequently focus on the physician as the major source of health related information. That over sixty percent of the women in this sample cited their health care provider as their first or second major source of information supports this assumption that providers are indeed major information sources. However, these context studies also generally suggest that health care consumers desire more information than they obtain from their physicians, ${ }^{3,12,16,26,27}$ and that physicians often underestimate both patients' desires for information and their level of knowledge. ${ }^{12,15,16,27}$ Thus, taken together, these findings suggest a large proportion of health care consumers are not receiving sufficient information from their health care providers.

On the other hand, while over $60 \%$ did cite their provider, nearly $40 \%$ of the women in this study, all of whom were enrolled in prenatal care, did not cite their provider either first or second. This is a sizable group who are obtaining their information elsewhere. Whether this is because of dissatisfaction with the amount of information offered by providers is only speculative. An alternative explanation is that these women shy away from questioning their health care providers and turn instead to family, friends, and other sources for information and answers to their questions. Other studies ${ }^{28,29}$ of information seeking also have found people use multiple sources for information. Thus, in order to develop strategies for ensuring accurate knowledge that is congruent with clients' information seeking practices, all health providers need to be more aware of the different information sources used by clients.

In particular, this study suggests providers need to consider the use of family as a major source of information by younger clients and by those from lower SES groups. This finding supports Suchman's ${ }^{9}$ view of an association between social group orientation and medical orientation. Women of lower SES used a more personal source of information, their families, whereas women of higher SES relied more on books, which are impersonal but perhaps more scientific and expert sources of information.

The increased use of self as a major source of information by women with previous pregnancy experience, while not unexpected, does highlight the need for careful assessment of a client's current knowledge. Such assessment should include both client desire for information and verification of the accuracy of existing information. Thus, providers need to take a more active role and initiate activities related to information giving even with women who have had other pregnancies.

The lack of significant relationships between general social support and the importance of any of the sources of information should be viewed within the context of the relatively extensive use of family and friends as sources of information. Clearly the availability and acceptability of these personal resources are prerequisite to their use as information sources. Indeed, when more specific measures of support were used, those who cited their families as more important also perceived more support from family members. Similarly, those who perceived more support from their providers cited their provider as a more important source of information than did those who perceived less support from their providers. 
Lastly, although providers do not routinely have access to locus of control measures, the results of this study support reasonable interpretations of the relationship between an individual's locus of control and information seeking behavior. Those women who scored higher on the powerful others health locus of control subscale viewed providers as more important and themselves as less important sources of information than did women who scored lower on this scale. Similarly, those who scored higher on internal health locus of control viewed providers as less important than those who scored lower on that subscale. The significant relationships between locus of control and the importance and use of media also were interesting. Those with higher internal locus of control sought out and used print media more than those with less belief in internal control, whereas those with higher belief in chance more often cited radio and television as their sources of information. This may reflect the fact that obtaining information from newspapers and magazines requires more direct action by the individual. On the other hand, information obtained from television or radio is more likely to be a chance occurrence.

Generalizations from this study are limited by the relatively high SES of the sample. In particular, the lack of a significant relationship between support and the importance of different sources of information may merely reflect the high availability of social support for this population. Similarly, the absence of effects for the interaction of one's value of health and one's internal locus of control may reflect this population's relatively high health status. Lastly, the necessity of excluding subjects appearing for their first prenatal visit or those in their ninth month of pregnancy potentially excluded subjects who were very late seekers of prenatal care. These limitations need to be considered in interpreting the results described here.

\section{CONCLUSION}

Despite a tendency to prefer either popular or scientific sources of information depending on SES, the multiple sources of information consulted by most of the women in this study included sources which reflect both of Suchman's medical orientations. The extent and methods of information search by pregnant women may reflect their recognition of a need to make decisions about health behaviors. Since the actual nature of the information obtained by these women is unknown, it is not possible to speculate here on its adequacy or accuracy. However, it is certainly possible that different information sources could provide conflicting information. This in turn could lead to health behaviors reflecting not only knowledge, but also individual decisions about the credibility of their sources of information.

Health educators need to consider both the population they are targeting and other sources of information that they may contradict and/or reinforce. Designs for information dissemination and health education research should consider the educational level of the targeted population not only because of obvious aspects such as reading level, but also in terms of the vehicles used for dissemination and study. Specifically, the results of this study suggest printed materials are more likely to reach pregnant women of higher SES, whereas television spots and office VCR programs may be better vehicles for women of lower SES.

This study clearly indicates that pregnant women use multiple sources of information. Consequently, educational packages need to be based on a careful community survey of cultural beliefs and general knowledge about health practices during preg- 
nancy. This will allow programs to respond to inaccurate beliefs and/or at least recognize when information disseminated is contradicting local beliefs held by the women themselves. friends, and family. Thus, the results of this study not only support previous theory and research about information seeking, but also particularly emphasize the need for health care providers and health educators to carefully consider the extent to which they and others may or may not be influencing clients" health behavior decision. making through giving and/or withholding information.

\section{References}

1. Aaronson LS: Health behavior in pregnancy: Testing a general model (Doctoral dissertation, University of Washington, 1983). Dissertation Abstracts International 44-11 A:3498, 1984.

2. DeVito AJ, Bogdanowicz J, Reznikoff $\mathrm{M}$ : Actual and intended health-related information seeking and health locus of control. J Personality Assess 46(1):63-69, 1982.

3. Lenz ER: Information seeking: A component of client decisions and health behavior. $A d v$ Nurs Sci 6(3):59-72, 1984.

4. McIntosh $\mathrm{J}$ : Processes of communication. Information seeking and control associated with cancer: A selected review of the literature. Soc Sci Med 8:167-187, 1974.

5. Hamburg DA, Adams JA: A perspective on coping behavior. Arch Gen Psy'ch 17: 277-284, 1967.

6. Messerli ML, Garamendi C, Romano J: Breast cancer: Information as a technique of crisis intervention. Am J Orthopsychiatry 50:728-731, 1980.

7. Punj GN. Staelin R: A model of consumer information search behavior for new automobiles. J Consumer Res 9:366-380, 1983.

8. Wagenaar WA, Keren GB: The seat belt paradox: Effect of adopted roles on information seeking. Org Beh \& Human Decision Processes 38:1-6, 1986.

9. Suchman EA: Social patterns of illness and medical care. J Health Hum Beh 6:2$16,1965$.

10. Geertsen R, Klauber MR, Rindflesh M, Kane RL, Gray R: A reexamination of Suchman's views on social factors in health care utilization. J Health Soc Beh 16: 226-237, 1975.

11. Langlie JK: Social networks, health beliefs, and preventative health behavior. $J$ Health Soc Beh 18:244-260, 1977.

12. Shapiro MC, Najman JM, Chang A, Keeping JD, Morrison J, Western JS: Information control and the exercise of power in the obstetrical encounter. Soc Sci Med 17:139-146, 1983 .

13. Midgley DF: Patterns of interpersonal information seeking for the purchase of a symbolic product. J Marketing Res XX:74-83, 1983.

14. Phillips LW, Sternthal B: Age differences in information processing: A perspective on the aged consumer. $J$ Marketing Res XVI:444-457, 1977.

15. Pratt L, Seligman A, Reader G: Physicians' views on the level of medical information among patients. Am J Pub Health 47:1277-1283. 1957.

16. Waitzkin H: Information giving in medical care. J Health Soc Beh 26:81-101, 1985.

17. Booth A, Babchuk N: Seeking health care from new resources. $J$ Health Soc Beh 13:90-99, 1972. 
18. Wilkinson CiS, Wilson J: An evaluation of demographic differences in the utilization of a cancer informative service. Soc Sci Med 17:169-175. 1983.

19. Wallston KA, Maides SA. Wallston BS: Health-related information seeking as a function of health-related locus of control and health value. $J$ Re's Personality 10 : 215-222, 1976.

20. Price-Greathouse J. Trice AD: Chance health-orientation and AIDS information seeking. Psych Reports 59:10,1986.

21. Trice AD, Price-Greathouse $\mathrm{J}$ : Locus of control and AIDS information-seeking in college women. Psych Reports 60:665-666, 1987.

22. Brandt PA, Weinert C: The PRQ-A social support measure. Nurs Res 30:277$280,1981$.

23. Wallston $K$, Wallston $B$, DeVellis $R$ : Development of the multi-dimensional health locus of control (MHLC) scales. Health Ed Mono 6:160-170, 1978.

24. U.S. Census: Census of the population and housing summary characteristics for government units and SMSA: Washington State. U.S. Commerce Department. 1980.

25. Heaney C, Aaronson LS: Health and health care in rural Washington. Seattle: Health Policy Analysis Program. University of Washington. 1981.

26. Faden RR. Becker C. Lewis C, Freeman J, Faden AI: Disclosure of information to patients in medical care. Med Care XIX:718-733, 1981.

27. McKinlay JB: Who is really ignorant-physician or patient? J Health Soc Beh 16: 3-11, 1975.

28. Hughes R. Durio HF: Patterns of childcare information seeking by families. Fam Relations 32:203-221, 1983.

29. Clair PA: Social networks and lay health related advice giving practices during pregnancy. Paper presented at the 114th Annual Meeting of the American Public Health Association 1986. 